\title{
Chapter 4 \\ Flood Management Policy in Shiga \\ Prefecture, Japan: Implementation \\ Approach of a Risk-Based Flood \\ Management System at Catchment Scale
}

\section{Kentaro Taki}

\begin{abstract}
Shiga Prefectural Government uses "site safety level" to assess the flood risk of major floodplains in the prefecture in order to implement an integrated floodplain management system in society. Site safety level is determined based on a risk matrix expressing the relationship between the frequency of inundation and the degree of damage at sites surrounding a river channel complex. A department has been set up for floodplain management separate from river management. The Department of Floodplain Management promotes disaster mitigation measures, such as land use and construction regulations, and conservation of traditional flood control facilities, including flood prevention forests, open levees, and ring levees. Such traditional facilities are highly functional as green infrastructure because they are focused not only on disasters but also on a daily basis in order to wisely utilize local ecosystem service.
\end{abstract}

Keywords Shiga Prefecture · Risk-based flood management · Risk assessment · Land use $\cdot$ Building regulation

\subsection{Changes in Flood Risk Management in Japan}

"Those who control the water, control the country." Flood control has been considered to be the basis of national administration since long ago, and the system for doing so has gradually changed over time to support the socio-economy of Japan.

Recently, the situation surrounding flood control has changed dramatically, and the risk of flooding is higher than ever before. Several challenges are emerging, including a decline in investment capacity owing to the decline in population,

K. Taki (殴

School of Environmental Science, Lake Governance Research Center, University of Shiga

Prefecture, Hikon, Shiga, Japan

e-mail: taki.k@ses.usp.ac.jp

(C) The Author(s) 2022

F. Nakamura (ed.), Green Infrastructure and Climate Change Adaptation,

Ecological Research Monographs, https://doi.org/10.1007/978-981-16-6791-6_4 
changes in social structure and lifestyles, decline in literacy regarding water-related disaster mechanisms, and an increase in extreme events associated with climate change. Against this background, it is important to understand how we can eliminate human casualties and avoid catastrophic damage that would make it difficult to rebuild livelihoods. We are currently confronted with the issues that contribute to the initiation of flood control.

The general measures that have been taken to minimize the risk of flood inundation so far, including basin and in-channel measures such as rainwater storage and infiltration facilities, river improvement, and flood control facilities, are not adequate. In addition to these, there is a need for a multilayered approach for flood disaster risk reduction measures in floodplains including the maintenance and development of flood flow control facilities such as flood prevention forests, open levee systems (combination of discontinuous levees and secondary levees), and ring levees as shown in Fig. 4.1, land use and building regulations, and further enhancement of flood prevention activities and evacuation guidance. Floodplain in this section refers to the area of a plain that is inundated by the overflow of water from a river channel or other source during a flood. In other words, floodplain refers to the entire area of a valley floor plain, alluvial fan, alluvial plain, or delta that is inundated by floodwater.

Measures in the floodplain are not a new approach to disaster mitigation. Flood control during the Sengoku period (Warring States period, late fifteenthlate sixteenth century) was based on defensive measures to prevent flooding as exemplified by open levees; flood mitigation measures based on the premise of inundation rather than continuous embankments were the mainstream measures. In the Edo period (1603-1867), as the development of new rice fields and the intensification of land use progressed, flood control by continuous levees gradually became the mainstream owing to improvements in civil engineering techniques. The River Law was enacted in 1898 against the background of the modernization of civil

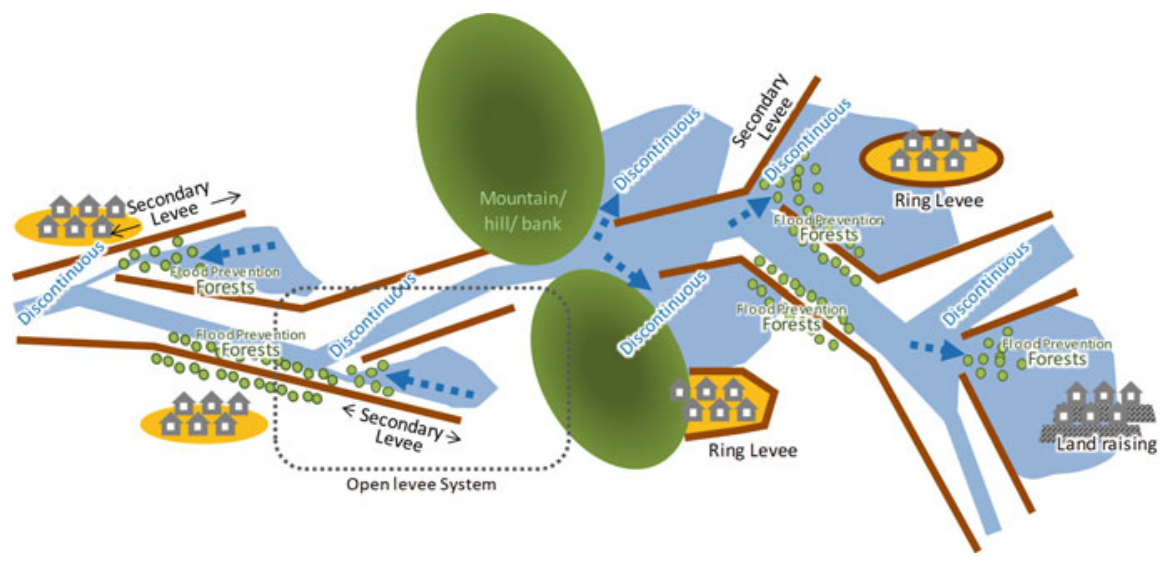

Fig. 4.1 Flood prevention forests, open levee system, and ring levees 
Table 4.1 Changes in modern flood control planning (based on Hori et al. 2008)

\begin{tabular}{l|l}
\hline $\begin{array}{l}\text { First stage } \\
\text { (largest recorded flooding) } \\
\text { (Late 1890s) }\end{array}$ & $\begin{array}{l}\text { The largest floods to date can be handled by the channels and } \\
\text { dam reservoirs without causing flooding }\end{array}$ \\
\hline $\begin{array}{l}\text { Second stage } \\
\text { (probable flooding) } \\
\text { Late 1950s) }\end{array}$ & $\begin{array}{l}\text { The designed external force for flood control facilities is } \\
\text { assessed according to the probability of exceeding the annual } \\
\text { maximum rainfall; rainfall of a certain probability scale is } \\
\text { used as the planned rainfall amount, and the main type of } \\
\text { hydrographs produced by this rainfall is handled by the river } \\
\text { channels and dam reservoirs without causing inundation }\end{array}$ \\
\hline $\begin{array}{l}\text { Third stage } \\
\text { (reduce inflow from the }\end{array}$ & $\begin{array}{l}\text { In addition to the measure of handling rainwater after it enters } \\
\text { the channels, alternative plans include measures in the } \\
\text { watershed to reduce the amount of rainwater that enters the } \\
\text { channels itself }\end{array}$ \\
$\begin{array}{l}\text { (Late 1970s) } \\
\text { Fourth stage } \\
\text { (flood risk management) } \\
\text { (2000s) }\end{array}$ & $\begin{array}{l}\text { Flood inundation is considered a premise, and alternative } \\
\text { plans take into account floodplain damage reduction measures } \\
\text { as well as watershed and channel facilities }\end{array}$ \\
\hline
\end{tabular}

engineering technology, and flood control systems using continuous levees became the basis for flood control in Japan. Currently, with the exception of a few nonurban rivers (e.g., Kita River in the Gokase River System (Miyazaki Prefecture), Kita River in the Kita River System (Fukui Prefecture), etc.), there are few flood control riparian forests that explicitly incorporate floodplain disaster mitigation measures.

Here, I would like to summarize the changes in flood control systems since the Meiji era. Hori et al. (2008) organized the changes in modern flood control planning in Japan into four stages (Table 4.1) and argued for the need to transition to the fourth stage. Flood control in the fourth stage is an expansion of flood control theory from the planning of watersheds (catchment areas) and river channels to encompass the entire basin including the floodplain, which is the affected area. This stage incorporates the concept of base defense into the continuous levee system.

Flood control in the fourth stage is based on the premise that flood inundation is a natural phenomenon; mitigation measures such as floodplain land use and housing practices can be considered as approaches to reduce damage by avoiding exposure and reducing vulnerability (Fig. 4.2).

\subsection{Flood Management Policy in Shiga Prefecture: Policy Formulation}

\subsubsection{The History of Wise Land Use and Urban Development: Hints from History}

The Amano River, which flows through Maibara City, Shiga Prefecture, was severely damaged by the Isewan Typhoon in 1959. Extensive riverbed excavation 
Fig. 4.2 Approaches to damage factors and mitigation, and mitigation measures in the floodplain reduce damage by avoiding exposure and reducing vulnerability. (Sources: Ministry of the Environment, Natural Environment Bureau 2016; ADRC 2015)

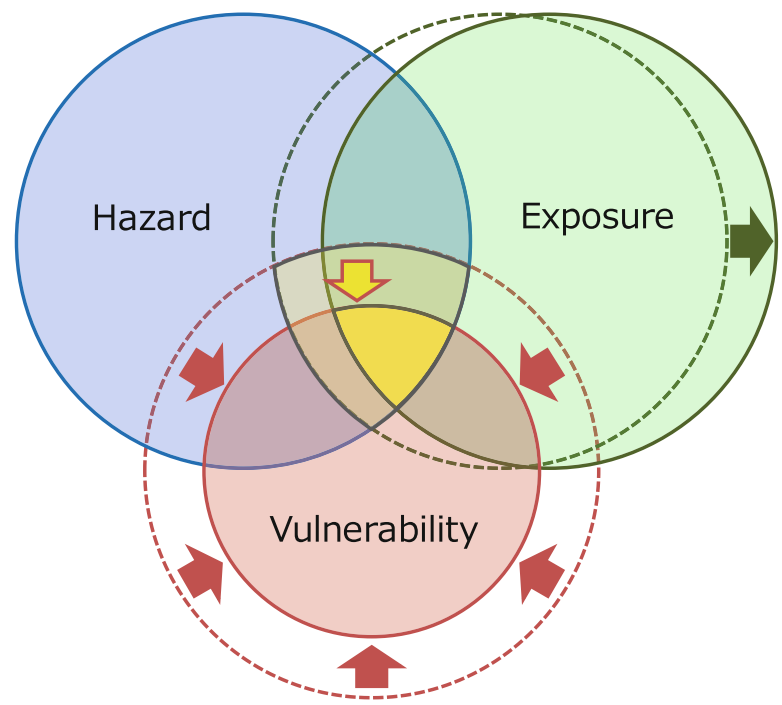

and revetment work was conducted in the recovery, but the prefectural public works office decided to keep the open levees. River administrators at that time well understood inundation characteristics and were also aware of excess flooding. The bullet train, Tokaido Shinkansen, crosses the Amano River. A railroad bridge was built across the river. Furthermore, in the sections of farmland, such as paddy fields, the viaduct extends instead of embankments, as shown in Fig. 4.3. Continuous embankments can interfere with the flow of floodwater and cause inundation. Therefore, bridges were built over non-riverine sections to allow floodwater to flow down through the section. The original track was planned with an embankment structure, but there was opposition from local residents against the embankment system owing to concerns about the retention of floodwater and inland water (Photo 4.1). In addition, the town of Kazuramaki in Higashiomi City, located near the confluence of the Hino River and the Hokyoji River, has autonomously raised the level of its residential land in conjunction with the height of its levees after restoration and repair based on its past experience with typhoons such as the Ise Bay typhoon. In areas where retention-type flooding occurs, such as at the confluence of a banked river, the frequency of outwash flooding is reduced by the embankments, but in the unlikely event that flooding does occur, floodwater and inland water may raise the depth of inundation to the height of the levee.

Inundation analysis throughout the prefecture showed that only approximately 1800 households would be submerged (inundated by more than $3.0 \mathrm{~m}$ ) even with a rainfall probability of once in 200 years (Taki et al. 2010). In addition, many of these houses were developed after the late 1940s. In contrast, many old settlements 


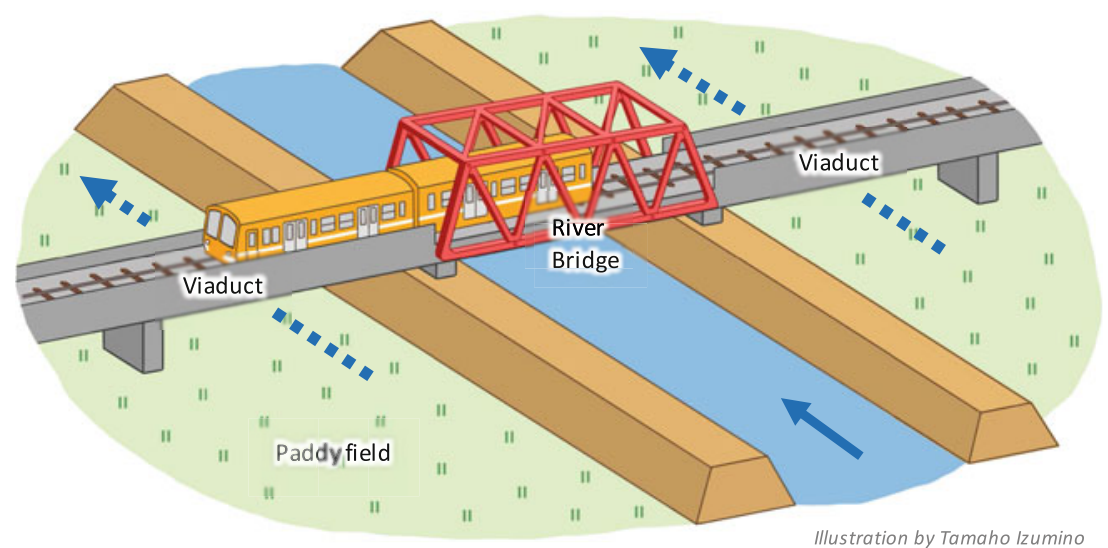

Fig. 4.3 Extension of the viaduct onto the paddy field so as to not block the flow of floods

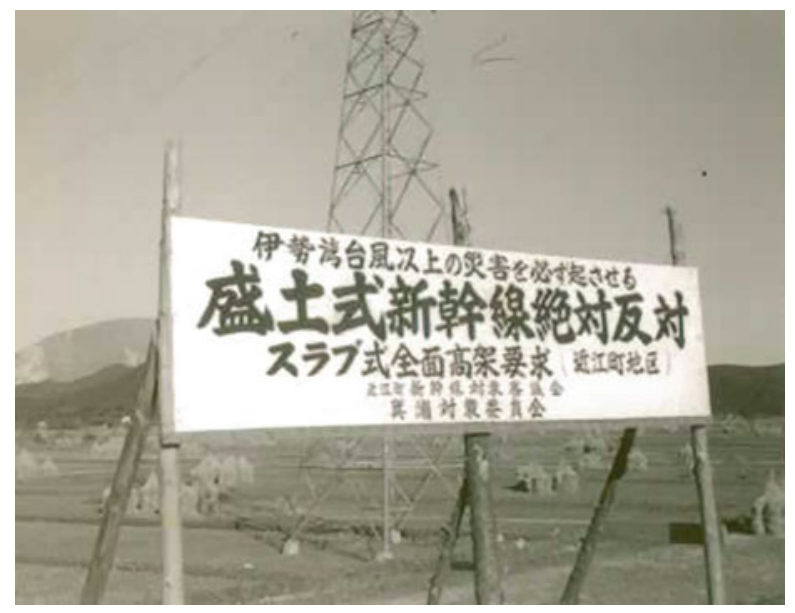

Photo 4.1 A sign opposing the embankment-type Shinkansen. (Source: Shiga Prefectural Government)

are located in slightly elevated areas such as natural levee belts (avoidance of exposure in Fig. 4.2) or have had measures implemented such as raising housing land (reduction of vulnerability in Fig. 4.2).

Several approaches described here were adopted in various parts of the prefecture and are still implemented in certain areas. However, with passage of time, many of these innovative measures have lost their importance. Open levees have also been gradually disappearing without their disaster mitigation effects being fully evaluated.

Until a few decades ago, river modification and urban development were linked. In the case of Lake Biwa, paddy fields are located on the lowlands around the river, 
and villages are located on very highlands such as natural levees. The result is a beautiful and rational landscape, harmonized with the providence of nature, in which the flow of the rivers and the positioning of farmlands and towns are all planned integrally. Such designs certainly made the best use of local resources or watershed ecosystem services given the size of the population and level of technology at the time.

\subsubsection{Policy Features: Process Management and Framework Design}

Shiga Prefecture's flood management policy began with the establishment of the Floodplain Management Office within the Public Works and Transportation Department in July 2006. This is a separate organization from the River Works Division.

In March 2012, approximately 6 years after its conception, the "Flood Risk Management Basic Policy in Shiga Prefecture" (hereinafter, "Basic Policy") was approved, and 2 years later, in March 2014, the "Flood Management Ordinance in Shiga Prefecture" was approved after rigorous discussions. The Flood Management Ordinance provides a legal basis for the Basic Policy and ensures the effectiveness of flood risk management measures conducted by Shiga Prefectural Government. The Basic Policy defines the objectives and measures of flood management in Shiga Prefecture as follows.

Flood risk management integrates self-help, mutual aid, and public assistance to comprehensively implement both in-river and off-river measures for flood risk management to avoid (1) loss of life (the highest priority) and (2) damage that makes it difficult to rebuild daily life after any kind of flood.

The responsibility for river management is stipulated in the River Law. The obligatory responsibility for flood control is understood to be "setting up design floods and ensuring that design floods flow safely through river channels." The obligatory responsibility for flood control is understood to be "setting up design floods and ensuring that design floods flow safely in the river channels." The Basic Policy includes such river management systems according to the River Law. The Basic Policy positions conventional river management as a core project and specifies that "basin retention measures," "floodplain disaster mitigation measures," and "measures to improve local disaster preparedness" are to be implemented to achieve the flood control goals set forth (Table 4.1). Beyond the framework of the River Law, the City Planning Act, Building Standards Act, and Flood Fighting Act were included in the scope of protection. The framework is to achieve the goal by 
covering the areas that cannot be addressed by river maintenance with the other three measures. Of the three measures, the "floodplain disaster mitigation measures," in particular, are intended to "avoid exposure" and "reduce vulnerability" to flood inundation.

\subsubsection{Site Safety Level: Basic Information for Policy Decisions}

When considering flood control measures, the scope of defensive measures should be expanded to include floodplain land use and housing practices in order to move into the fourth stage of flood control. In addition, it is necessary to directly weigh the risks of the floodplains newly subject to planning. In other words, floodplain risk is the frequency at which a certain kind of damage occurs at each point surrounded by a river/channel complex. For example, if you buy the house shown in Fig. 4.4, you may be more concerned about how often and to what degree your home would be flooded rather than the individual safety of the rivers and waterways that surround it. The risk at each site surrounded by a river/channel complex in this way is referred to as the "site safety level" by SPG.

Site safety level can be calculated from hydraulic parameters (inundation depth and speed and fluid force) obtained from flood hydraulic analysis. For example, it is possible to express the site safety level as a risk matrix, as shown in Fig. 4.5, according to the frequency of damage and degree of damage at each point. The magnitude of damage can be classified into five levels: level $1(h \leq 0.1 \mathrm{~m})$ indicates no damage; level $2(0.1 \leq h \leq 0.5 \mathrm{~m})$ indicates damage from inundation below the ground floor of a building; level $3(0.5 \leq h<3.0 \mathrm{~m})$ indicates severe damage from inundation above the ground floor; level $4(3.0 \leq h)$ indicates fully submerged; and level $5\left(2.5 \mathrm{~m}^{3} / \mathrm{s}^{2} \leq u^{2} h\right)$ indicates completely destroyed. The probability of occurrence of each flood event was evaluated by means of its return period, namely, $2,10,30,50,100,200,500$, and 1000 years, where $h$ is depth $(\mathrm{m})$ of the inundation and $u$ is velocity (m/s). The term $u^{2} h$ means the "fluid force."

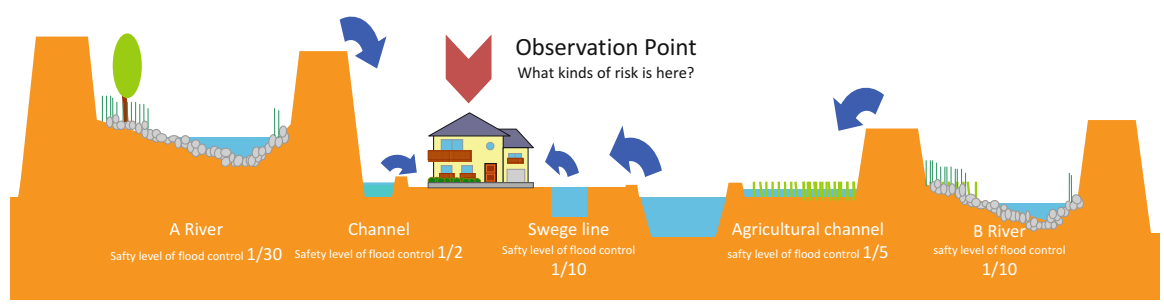

Fig 4.4 Site safety level. This is the level of safety of a point surrounded by a river/channel complex and for the setting of daily life (Source: Taki et al. 2010) 


\begin{tabular}{|c|c|c|c|c|c|c|c|}
\hline$-1 / 2$ & $(0.500)$ & \multirow{8}{*}{ 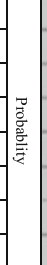 } & & & & & Pil \\
\hline$-1 / 10$ & $(0.100)$ & & & & & & \\
\hline$-1 / 30$ & $(0.033)$ & & & & & & \\
\hline$-1 / 50$ & $(0.020)$ & & & $\mathrm{x}$ & $\mathrm{x}$ & & \\
\hline$-1 / 100$ & $(0.010)$ & & & & & & \\
\hline$-1 / 200$ & $(0.005)$ & & & & & $\mathrm{x}$ & $\mathrm{x}$ \\
\hline$-1 / 1000$ & $(0.001)$ & & & & & & \\
\hline \multirow[t]{4}{*}{$1 / \infty$} & $(0.000)$ & & Lowe & R RISK & & & \\
\hline & & & \multicolumn{5}{|c|}{ Damage Level } \\
\hline & & & 1 & 2 & \begin{tabular}{|l|} 
\\
\end{tabular} & 4 & 5 \\
\hline & & & $h<0.1 \mathrm{~m}$ & $\begin{array}{r}0.1 \mathrm{~m} \leq h \\
\quad<0.5 \mathrm{~m} \\
\end{array}$ & \begin{tabular}{|c|}
$0.5 \mathrm{~m} \leq h$ \\
$<3.0 \mathrm{~m}$
\end{tabular} & $3.0 \mathrm{~m} \leq h$ & $\begin{array}{l}u^{2} h \geq \\
2.5 \mathrm{~m}^{3} / \mathrm{s}^{2}\end{array}$ \\
\hline
\end{tabular}

The figure on the left shows the following for an ordinary house at the location in question

Damage Lv. 5 House washout occurs about once every 200 years

Damage Lv.4 Inundation above roof level occurs about once every 200 years

Damage Lv.3 Inundation above floor level occurs about once every 50 years

Damage Lv. 2 Inundation below floor level occurs about once every 50 years

$h$ : inundation depth $(\mathrm{m})$ $u$ : flood flow velocity $(\mathrm{m} / \mathrm{s})$.

Fig 4.5 Site safety level at a point expressed using a risk matrix (Taki et al. 2010; Shiga Prefectural Government 2012)

SPG has developed and published a numerical analysis model for evaluating site safety level (Taki et al. 2013). The basic requirements of this numerical analysis model are as follows:

Requirement 1: Consider combined flooding from the river/channel complex surrounding a site on the floodplain (living sphere).

Requirement 2: Consider high- to low-frequency inundations (multiple occurrence probabilities).

Requirement 3: Be able to evaluate risk/safety level equally by policy units (in this case the entire prefecture).

Requirement 1 indicates that the model evaluates the risk/safety level at each location on the floodplain, rather than performance of each river levee or other disaster prevention facility. The model evaluates the performance of the system as a whole group of disaster prevention facilities rather than individual facilities. SPG incorporates (rainwater) sewage systems and agricultural drainage channels into the model besides the 240 major rivers and analyzes them in an integrated manner. Requirement 2 is to assess damage based on the frequency (or magnitude) of floods. Since administrative measures must be impartial within a jurisdiction, requirement 3 allows assessments by administrative units, such as prefectures and municipalities, in the same way.

The structure of the numerical analysis model and the flow of calculations are shown in Fig. 4.6 (Taki et al. 2019) and Fig. 4.7 (Taki et al. 2010). Although the calculation algorithm is orthodox, the most distinctive feature of the model is that it integrates data from not only major rivers managed by the national and prefectural governments but also from small rivers, (rainwater) sewage systems with different management categories, and agricultural drainage.

Modeled rainfall events with a probability of occurrence once in 2, 10, 30, 50, 100, 200, 500, and 1000 years estimated from the Shiga Prefecture rainfall intensity equation are used as the external force for the calculation. 


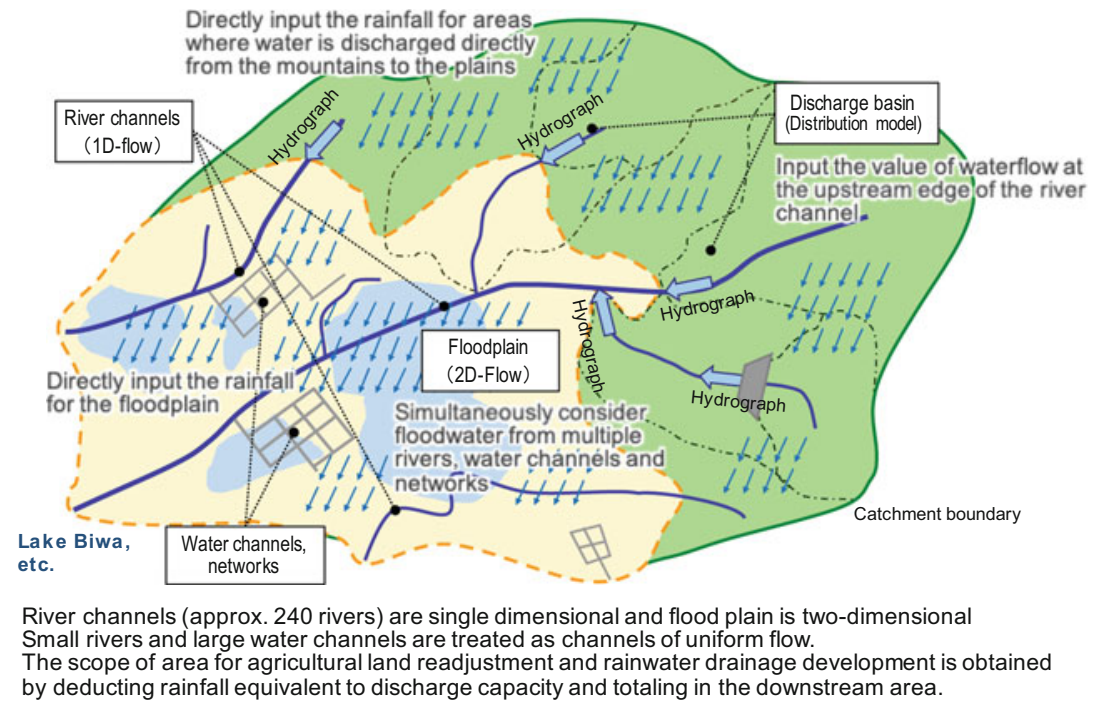

Fig 4.6 Composition of the numerical analysis model (Source: Taki et al. 2019)

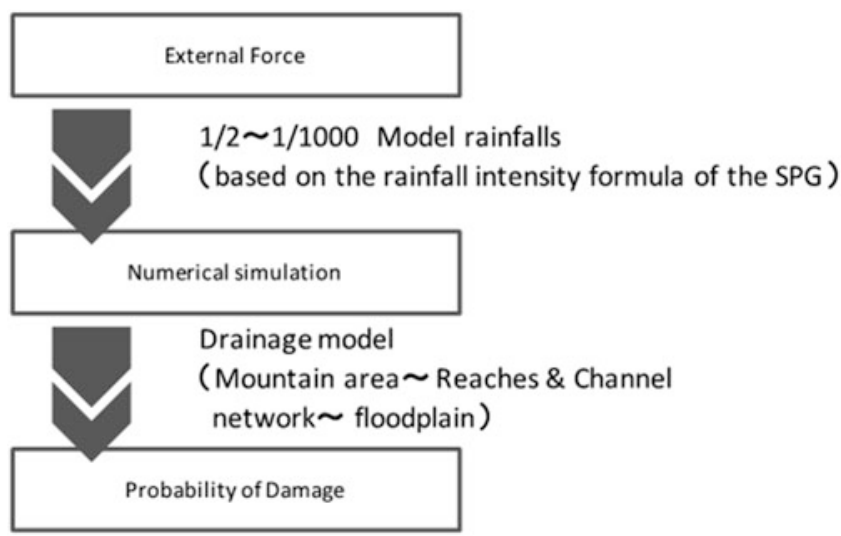

Lv. $1 \sim \operatorname{Lv.5}$

Fig 4.7 Flow of calculations (Taki et al. 2010)

Some of the calculation results are shown in Figs. 4.8 and 4.9. For official prefectural site safety level data, see the Shiga Prefecture disaster preparedness information map (https://shiga-bousai.jp/dmap). GIS data (shapefiles) are available along with maps of areas of possible inundation for each river.

The flood hazard maps published by local governments across the country usually show the depth of inundation for each river in the event of a design flood as an assumed external force. Recent amendments to the Flood Fighting Act in 2015 mandated the designation of areas with a high probability of inundation in the 


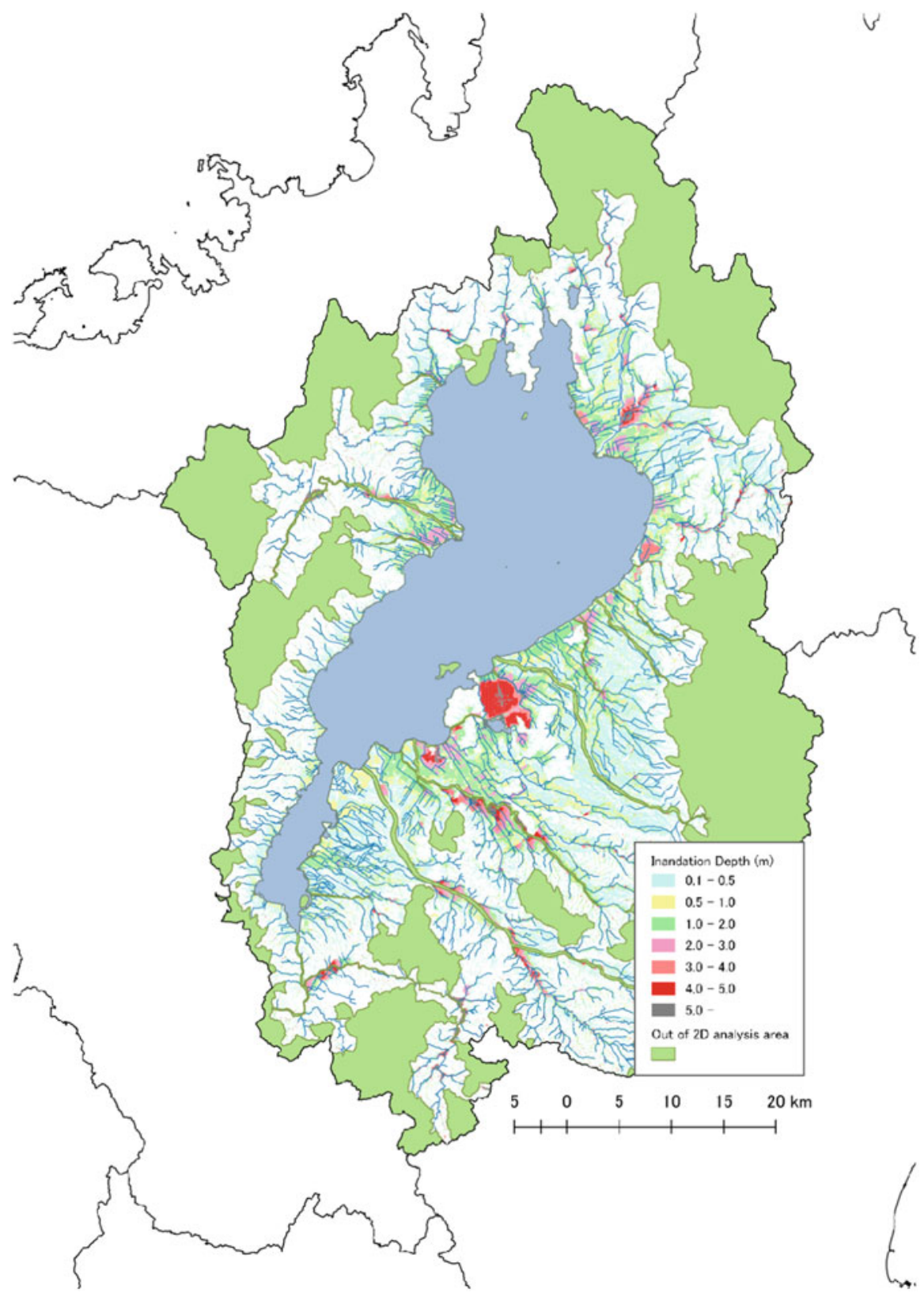

Fig 4.8 Maximum inundation depth (1000-year flood) (Source: Taki et al. 2019) 


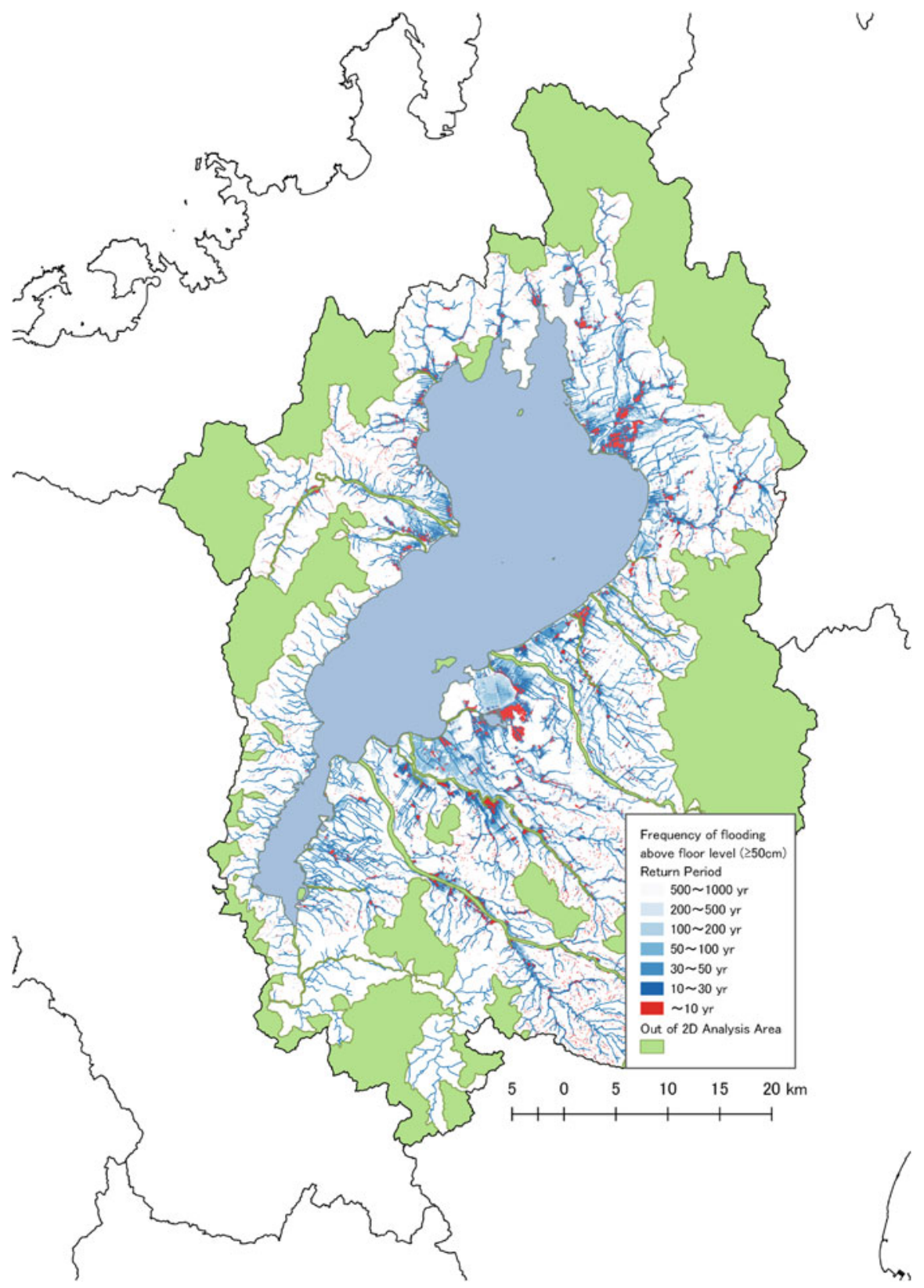

Fig 4.9 Frequency of inundation above floor level ( $\geq 50 \mathrm{~cm}$ ) (Source: Taki et al. 2019) 
maximum expected scale of flooding and led to an urgent need to review inundation assumptions and hazard maps across the country. The assumed maximum size is often calculated as the equivalent of an event that has a probability of occurring once in 1000 years. Despite this increased awareness of excessive flooding in inundation assumptions, it is not yet common to express flood risk in a matrix of "frequency of inundation" and "degree of damage" as in the case of "site safety level."

Based on this "site safety level," SPG has developed disaster mitigation measures for floodplains.

\subsubsection{Floodplain Disaster Mitigation Measures}

One of the floodplain disaster mitigation measures in the Basic Policy was to regulate land use and building in high-risk locations. As shown in Fig. 4.10, Area A is "in principle not included in the urbanization promotion area" in order to avoid "severe property damage." In Area A, inundation on the floor occurs frequently, causing economic damage that makes it difficult to rebuild lives. Area B requires "a structure with a floor higher than the expected inundation level to which evacuation is possible" or "a strong structure that will not be washed out by the expected fluid force" for building permits to avoid house washout and submersion that directly lead to human suffering (regulations based on fluid force are not yet in operation (as of July 2021)). In Area B, even if the frequency is rather low, human damage such as submersion or loss of houses will occur.

However, with the enactment of the Omnibus Decentralization Act in 2000, both of the above notifications were redesignated as legally nonbinding technical advice. Therefore, SPG enacted a Flood Management Ordinance (March 31, 2014, SPG Ordinance 55) to clarify the legal basis for regulation. In addition, FloodResistant Building Guidelines (2015) were established to provide building permit requirements under the Flood Management Ordinance.
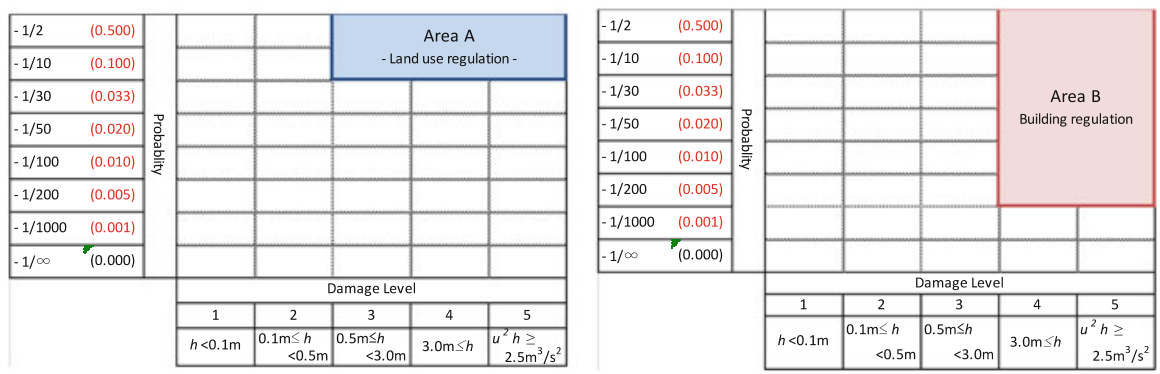

Fig 4.10 Scope of risk covered by land use (Area a) and building regulations (Area b) (Source: Taki et al. 2010; Shiga Prefectural Government 2012) 
Land use and building regulations are nothing more than restrictions on the private property rights guaranteed by the Constitution. In other words, the strength of the regulations must be kept to a minimum in light of the socially accepted norms at the time and after due consideration of the public interest to be secured, such as the protection of life and property. Policy and legal considerations are critical when applying a regulatory approach. Simply discussing the need without fully identifying institutional common ground does not lead to social implementation.

Furthermore, floodplain disaster reduction measures impose a duty of care on developers to ensure that the installation of continuous embankment structures, such as road projects, does not cause significant changes in flood zones, for example, by making bridges over floodplain. The "Guidelines for installation of embankment structures pursuant to Article 25 of the Flood Management Ordinance (2015)" have been released as technical standards. The preservation of open levees, which serve as flood flow control facilities, and the development of armor levees are included in the statutory river improvement plans for each area in the prefecture.

\subsection{Floodplain Management and Green Infrastructure}

\subsubsection{Establishing a "Floodplain Manager": Social Implementation and Points of Practice}

Among the four measures for flood risk management (Table 4.2), river improvements (river works) and basin storage measures (retention measures) primarily aim to reduce the frequency of flood inundation through structural measures (levees and flood control facilities) in the basin and river channel area. For river improvements in particular, the River Law and related laws and regulations, as well as major court cases, such as the Daito flood lawsuit and the Tama River flood lawsuit, have clarified the scope of obligatory liability for facility management. Most basin storage measures are installed by developers in accordance with prefectural ordinances and guidelines, but some are positioned in river plains within the framework of comprehensive flood control projects and installed by river administrators such as public works offices of the Ministry of Land, Infrastructure, Transport and Tourism or prefectural governments.

Measures to improve local disaster preparedness (preparation measures) have been developed mainly by local governments with the support of river administrators under various systems related to crisis management, such as the Flood Fighting Law and the Disaster Countermeasure Basic Law, as a complementary measure to river maintenance and basin storage measures.

In contrast, floodplain disaster mitigation measures (containment measures) such as open levees, two-line levees, forest protection, and land use and building 
Table 4.2 Classification of flood management measures (Shiga Prefectural Government 2012)

\begin{tabular}{l|l}
\hline $\begin{array}{l}\text { River works } \\
\text { Measures to ensure safe flow } \\
\text { of design floods in river } \\
\text { channels }\end{array}$ & $\begin{array}{l}\text { Measures to improve rivers and waterways in order to prevent } \\
\text { floods from river overflowing. These include artificial levees, } \\
\text { reservoirs, and flood control dams }\end{array}$ \\
\hline $\begin{array}{l}\text { Watershed works } \\
\text { Basin retention measures }\end{array}$ & $\begin{array}{l}\text { Measures to mitigate rapid flood runoff into rivers and } \\
\text { waterways. These include rainwater retention in ponds, } \\
\text { grounds, forest soils, paddy fields, and reservoirs }\end{array}$ \\
\hline $\begin{array}{l}\text { Floodplain works } \\
\text { Flood disaster reduction } \\
\text { measures }\end{array}$ & $\begin{array}{l}\text { Urban planning measures to minimize damage in the event of } \\
\text { flooding that exceeds the capacity of river and waterway } \\
\text { facilities. These include ring levees, secondary levees, flood } \\
\text { prevention forests, land use regulations, and building flood } \\
\text { proofing }\end{array}$ \\
\hline $\begin{array}{l}\text { Community works } \\
\text { Disaster resilience } \\
\text { improvement }\end{array}$ & $\begin{array}{l}\text { Measures to support evacuation and flood prevention } \\
\text { activities. These include disaster drills and the dissemination } \\
\text { of disaster preparedness information }\end{array}$ \\
\hline
\end{tabular}

regulations have long been adopted as risk reduction measures but have not been fully taken into account in modern flood control systems. The open levee, which is said to have been developed by Shingen Takeda (1521-1657, a famous territorial lord), was seen in many places in the past, but many of them have now disappeared without finding a place in the current institutionalization. With regard to land use, the risk of flooding in the area has not been treated as a major determinant during subsequent annexation of an existing residential zone into an urbanized zone or during the conversion of agricultural land.

Under the current legal system, the primary responsibility of river management is to handle design floods within river channels. Therefore, when floodplain disaster mitigation measures are implemented by river administrators, they have to be implemented as an extension of river management for the purpose of handling design floods. This means that part of the floodplain is considered a river channel (river management facility) and used to handle design floods. For example, ring levees and secondary levees that are constructed as part of a land use integrated water disaster prevention project fall under this category. That is, the current position is different from the idea that disaster mitigation is accomplished by responding throughout the floodplain (floodplain management) rather than by using river management facilities.

However, the current flood control system has been deeply adapted to the socioeconomic needs of Japan since the enactment of the River Law in 1898, with modifications added as necessary. Dramatically altering the system would cause social friction and confusion. A practical and appropriate approach to floodplain disaster mitigation practices, therefore, is to respect the various plans implemented by river administrators as a given condition and add a separate system of administration (floodplain managers) to complement them.

To enable the establishment of a complementary relationship, floodplain managers should be given the objective of minimizing damage from external forces 
beyond the capacity of facilities, regardless of the stage of river maintenance. A separate system of administrative procedures (legal, organizational, and budgetary measures) of river management should also be added.

Based on this idea, SPG established the goals and system of flood risk management as mentioned in Sect. 4.2. Specifically, an independent department in charge of river basin-wide flood management (Floodplain Management Office) was established, which is separate from the department in charge of rivers (River and Port Division). This was successful, and floodplain disaster mitigation measures can now be promoted in parallel with river maintenance, rather than as a binary choice.

\subsubsection{Artificial Structures and Green Infrastructure}

The Science Council of Japan (2014) describes the benefits of artificial structures as "achieving a single function that contributes to a specific and distinct purpose with a high degree of precision (accurately providing the performance required by the society)," and the benefits of green infrastructure as "maintaining and creating diverse spaces that can provide a variety of ecosystem services and contribute to the conservation of biodiversity." Green infrastructure should be understood as complementing rather than replacing the function of artificial structures.

In terms of the sole function of flood protection, green infrastructure is nowhere near the standard of artificial structures. Nonetheless, although green infrastructure may be less effective in a specific function, it exhibits diverse functions in normal times. For example, there are still some flood prevention forests along the Azumi River, which runs through the western part of Shiga Prefecture. Many are bamboo groves, which not only mitigate flooding but also support rich riverine biota, provide food, and have been used as materials to make the frames of traditional Japanese fans and the like. In this way, green infrastructure, which is closely related to lifestyle and culture, is itself a local resource and forms the character of the region and its original landscape. This is a role that could not easily be played by functionally oriented concrete embankments.

In advancing flood control policy, it is essential to find the best combination of artificial structures and green infrastructure in accordance with the legal system and regional characteristics, considering the characteristics of each.

\subsubsection{Green Infrastructure: The Trump Card in Floodplain Management}

To ensure that administrative responsibilities are fulfilled under the river management system based on River Law, artificial structures such as levees and dams 
that reliably perform the required functions are essential. In contrast, attempts to build artificial structures to prevent excess floods are met with irrefutable policy arguments from the fiscal authority that the responsibility of dealing with design floods should first be executed before engaging in excess flood control measures. Therefore, in this author's view, floodplain management must focus on a response with green infrastructure that can perform a variety of functions during normal times. From the above, the scope of defense by artificial structures and green infrastructure can be summarized as follows.

River management: continues to play a role in ensuring the safe flow of design floods within river channels, based on reliably functioning artificial structures to reduce the frequency of flood inundation. Promote nature-oriented river development to the extent that it does not impair flood control functions with respect to design floods.

Floodplain management: addresses floods that exceed the capacity of artificial structure complexes through Eco-DRR-oriented green infrastructure, including land use, with a focus on "avoiding exposure" and "reducing vulnerability".

As we have seen, Eco-DRR-oriented green infrastructure has a strong affinity with floodplain disaster mitigation measures, but we cannot expect to see a large amount of public investment on the so-called "extra" measures when river management is still in its infancy. In addition, many of the current laws, such as the Rivers Act, the Cropland Act, and the Forest Act, are organized according to purpose. Hence, it is inherently difficult to develop something as multifaceted as green infrastructure within a single legal framework. It is an issue of vertical compartmentalization.

However, in the face of a declining population and climate change, we must establish methods to solve problems by going beyond the vertical division of the legal system and the administrative structure. For example, the disaster mitigation effects and multifaceted functions of Eco-DRR-oriented green infrastructure should be evaluated, and the ways to raise funds directly from financial markets should be considered. I expect research for social implementation to rapidly advance from now on.

\section{References}

ADRC (2015), Total disaster risk management - good practices

Hori T, Furukawa S, Fujita A, Inazu K, Ikebuchi S (2008) An optimal design framework of a flood control system including in-floodplain countermeasures based on distributed risk assessment - basic concepts and methodology. Jpn Soc Civil Eng 64(1):1-12. [in Japanese with English abstract]

Natural Environment Bureau, Ministry of the Environment (2016) Approaches to disaster reduction and mitigation using ecosystems [in Japanese]

Science Council of Japan (2014) Proposal: recommendations for the use of ecosystem infrastructure in reconstruction and national resilience [in Japanese] 
Shiga Prefectural Government (2012) Flood management basic policy in Shiga prefecture [in Japanese]

Shiga Prefectural Government (2014) Flood management ordinance in Shiga prefecture. Shiga Prefecture Ordinance No 55, March 31, 2014 [in Japanese]

Taki K, Matsuda T, Ukai E, Ogasawara Y, Nishijima T, Nakatani K (2010) Design for flood disaster-reduction system in a floodplain of small-medium sized rivers. Adv River Eng 64:477482. [in Japanese with English abstract]

Taki K, Matsuda T, Ukai E, Nishijima T, Egashira S (2013) Method for evaluating flood disaster reduction measures in alluvial plains. J Flood Risk Manag 6:210-218

Taki K, Yamashita K, Hirayama N, Takanishi S (2019) A study of regional disaster preparedness improvement strategy based on hydraulic analysis of a small and medium-sized river system. Adv River Eng 25:79-84. [in Japanese]

Open Access This chapter is licensed under the terms of the Creative Commons Attribution 4.0 International License (http://creativecommons.org/licenses/by/4.0/), which permits use, sharing, adaptation, distribution and reproduction in any medium or format, as long as you give appropriate credit to the original author(s) and the source, provide a link to the Creative Commons license and indicate if changes were made.

The images or other third party material in this chapter are included in the chapter's Creative Commons license, unless indicated otherwise in a credit line to the material. If material is not included in the chapter's Creative Commons license and your intended use is not permitted by statutory regulation or exceeds the permitted use, you will need to obtain permission directly from the copyright holder. 